\title{
Google Translate as a Supplementary Tool for Learning Malay: A Case Study at Universiti Sains Malaysia
}

\author{
Hossein Bahri (Corresponding author) \\ School of Languages, Literacies and Translation, Universiti Sains Malaysia, Malaysia \\ E-mail: hobahri@yahoo.com \\ Tengku Sepora Tengku Mahadi \\ School of Languages, Literacies and Translation, Universiti Sains Malaysia, Malaysia \\ Doi:10.7575/aiac.alls.v.7n.3p.161 \\ Received: 16/01/2016 \\ URL: http://dx.doi.org/10.7575/aiac.alls.v.7n.3p.161 \\ Accepted: 20/03/2016
}

\begin{abstract}
The present paper examines the use of Google Translate as a supplementary tool for helping international students at Universiti Sains Malaysia (USM) to learn and develop their knowledge and skills in learning Bahasa Malaysia (Malay Language). The participants of the study were 16 international students at the School of Languages, Literacies, and Translation, USM who had registered for the LKM 100 Bahasa Malaysia (I) course. Based on the literature review, analysis of the collected data, and an assessment of the course content and activities inside and outside the language classroom, the findings suggest that most international students at USM recognize Google Translate as an effective supplementary tool for learning vocabulary, writing, and reading in Bahasa Malaysia. In fact, some students reported that they could optimally benefit from their self-learning if they were assisted to use Google Translate effectively. Moreover, using Google Translate for doing classroom tasks and activities can encourage students to study independently, and to shape their own strategies for solving language learning problems.
\end{abstract}

Keywords: Google Translate, supplementary tool, translation, language learning, Bahasa Malaysia

\section{Introduction}

Since the birth of Grammar-Translation Method in the mid nineteenth century researchers have long investigated the use of translation as a methodology for learning language skills such as reading, writing, grammar and vocabulary (Richards, 2001). The advent of new electronic tools and technologies has profoundly transformed earlier methodologies, providing both language learners and teachers with new avenues to explore in the field of language learning (Tabatabaei \& Gui, 2011; Roche, 2010). Some scholars (Dagiliene, 2012; Cook, 2010) believe that due to the needs and realities of the current globalized world there is a revival of translation approaches to language learning and teaching.

Within the last few years, one technology that has amply helped learners to develop their language learning skills is Google Translate, or GT. Indeed, millions of people around the world use the service for translation on a daily basis and a growing number of language learners are using it for language learning purposes. However, the advantages and potentials of this new technology for language learning have recently been explored by few researchers (Groves \& Mundt, 2015; Jin \& Deifell, 2013; Garcia \& Pena, 2011; Josefsson, 2011). Meanwhile, some teachers express misgivings about the way we prepare students for how to deal with these technologies both inside and outside the classrooms (Davis, 2006; Watkins, 2004).

Google Translate is a free machine translation service made available by the Google Company for translating texts and messages from one language into another. Currently it is accessible through a web interface along with smart phone apps/interfaces and application programming interfaces (APIs) that can fit into new software. As of 2016 GT supports more than 100 languages (Google Translate, 2016). Google Translate is based on Statistical Machine Translation, which works by analyzing hundreds of millions of natural bilingual text pairs (Koehn, 2009). These natural pairs can serve as authentic examples of language use from the languages involved.

In a study of the writings of a group of beginner learners with low language proficiency Garcia \& Pena (2011) found that these learners could benefit from using machine translation more than the high proficiency learners and there was evidence that they preferred to use it even against the will of their instructors. Interestingly, they discovered that using machine translation also helps beginner learners to better communicate among themselves.

Josefsson (2011) studied the strategies and attitudes of some vocational training students towards translation in language learning. She concluded that as a supporting tool on students mobile phones, Google Translate performed better than the traditional dictionaries with its higher speed and accuracy particularly for translation of collocations, phrases, and technical words. Concerning the reading comprehension of the passages they worked on, it also provided a general gist of the meaning of the text. The students were analytically aware of their own learning as they used Google 
Translate leading to the production of more coherent texts by the learners. Nevertheless, she found that Google Translate proved less useful for providing grammatical solutions.

Another research by Jin \& Deifell (2013) showed that as an online dictionary, Google Translate was the second most widely used online tool by language learners because of its convenience. Still, they concluded that learners generally used Google Translate as a supplementary tool to online dictionaries due to its lack of grammatical explanation. The findings of their study confirms that learners believe the use of online tools such as Google Translate accelerates their reading and writing skills in the foreign language while reducing their learning anxiety. However, the researchers treat the new findings with caution as online dictionaries fail to provide the students with clear explanations and generally ignore the contexts.

Most recently Groves \& Mundt (2015) stressed the implications of using machine translation technologies like Google Translate for doing tasks and assignments in second language learning. In a study of a sample of students of English for academic writing, they asked the participants to write an essay in their own native language and then these essays were translated using Google Translate, which showed that the machine translation version, while having errors and weaknesses, was comprehensible and close to the minimum level demanded by most institutions for university admission. In fact, the authors of the study believe that Google Translate can have a great influence on the teaching of Languages for Academic Purposes for both the students and their teachers; hence instructors in the field of language teaching need to work with, not against, these technologies.

The current study aims to investigate the use of Google Translate as a supplementary tool in helping international students at Universiti Sains Malaysia (USM) to learn and develop their knowledge and skills in learning Bahasa Malaysia and also to explore the advantages and/or disadvantages of Google Translate application through an analysis of their subjective comments regarding its use in the LKM 100 Bahasa Malaysia (I) course. Therefore the following research questions are addressed:

1. What are the selected learners' attitudes towards using Google Translate as a supplementary tool in language learning?

2. Is there any significant relationship between selected learners' overall scores in the Google Translate attitude questionnaire and their midterm examination scores?

3. How do selected learners perceive the benefits and/or problems of using Google Translate as a supplementary tool in language learning?

\section{Method}

The current research is a case study that investigates the use of Google Translate as a supplementary tool in helping international students at Universiti Sains Malaysia (USM) to learn and develop their language learning capabilities in Bahasa Malaysia. The university requires that all international students whose native languages are other than Malay take and pass the LKM 100 Bahasa Malaysia (I) course with a minimum grade of $\mathrm{C}$ before their graduation.

\subsection{The LKM 100 Bahasa Malaysia (I) Course Syllabus}

As stated in "A Guide to Language Courses" published by the School of Languages, Literacies and translation, the LKM 100 Bahasa Malaysia (I) Course Syllabus (2014):

...is a beginner level Malay course, in which the students are taught pronunciation according to the Malay Language Sound System. They are also introduced to basic grammar and trained to write simple sentences. A list of about 500 words is introduced. These include nouns, verbs, adjectives and function words. This course enables students to use basic language structures for daily conversations in a variety of situations. Students are also exposed to the Malay culture (p. 27). ... The evaluation of a course is based on continuous assessment in the form of coursework and the final examination. Coursework evaluation includes classroom and out-of-class assignments, midterm examination, essays, oral presentations and participation in tutorials (ibid: p. 10).

The following table shows a summary of the course information and examination duration. Students are required to attend classes two days a week for a total of four hours and their assessment is based on a $50 \%$ coursework and $50 \%$ final examination.

Table 1. Course information and examination duration

\begin{tabular}{cccccc}
\hline Course & $\begin{array}{c}\text { No. of } \\
\text { Units }\end{array}$ & $\begin{array}{c}\text { No. of contact } \\
\text { hours per week }\end{array}$ & $\begin{array}{c}\text { Coursework \& Examination } \\
\text { Contribution (\%) }\end{array}$ & $\begin{array}{c}\text { Examination } \\
\text { Duration } \\
\text { (hour) }\end{array}$ \\
\hline $\begin{array}{c}\text { LKM 100 Bahasa } \\
\text { Malaysia (I) }\end{array}$ & 2 & 4 & $50 \%$ & $50 \%$ & 2 \\
\hline
\end{tabular}


The medium of instruction in the LKM 100 Bahasa Malaysia (I) course is English used by native Malay teachers whose own second language is English. All international students are generally required to have an IELTS band score of at least 6 or its equivalents in other internationally-recognized tests depending on their field of study. Therefore, it is supposed that all registered students are at an acceptable level of English language proficiency.

The teacher often uses the course book, pictures, handouts in addition to the whiteboard handwritings and sometimes PowerPoint files to present the content. The Internet is available through $\mathrm{Wi}$-Fi connections in the classrooms and nearly all students have smart phones or laptops. In the introductory sessions the teacher will teach the Malay phonetic system using examples of those sounds in English words. Wherever the sounds are different s/he usually acts out the sounds just as the Malay people do. The course book units normally start with a set of vocabulary and phrases followed by a situational dialogue for memorization. The English translation of the dialogue is provided underneath. After each text the English translations of new words and expressions are provided. The topic of units include greetings, congratulations; talking about numbers, time and money; calendar, time prepositions; objects and their classifiers; types of adjectives; family and relationships; jobs; place prepositions; daily activities; and the country (Malaysia). This indicates that the book is based on a mixed or multi-strand (Ur, 1996) syllabus in which topics, functions, notions, grammar, and vocabulary are presented.

The students usually start with the written form of Malay by reading the sentences written by the teacher on the board or from their textbooks. As the students proceed with learning more basic lexical items and function words the units will include some basic aspects of Malay grammar, which is generally considered to be easy and straightforward by most students. The sentence is the basic unit of language instruction but it is often contextualized. Since the learners are all adults, grammar is generally taught deductively. Later, the students will do various types of classroom exercises called "Latihan". They are asked to collaborate in doing them in the classroom and more exercises will be done out-of-class.

In-class activities include reading texts one by one and doing exercises in collaboration with others. At this point students can use Google Translate to understand the meaning of words and then answer individually. The students positively influence the learning of others by helping each other to solve the problems. The teacher also encourages students to volunteer for doing the exercises and checks their assignments. Pronunciation errors are tolerated but lexical and grammatical errors are corrected by the teacher or peers. In the final sessions the students are asked to make an oral presentation of the topics covered during the course, though reading and writing are the main focus of attention.

The students are encouraged to study the next unit on their own before coming to the class so that they can readily participate in classroom activities. This needs much preparation and self study on the part of the students. English translations of many words are provided throughout the book usually the first time they appear in a text but they are not listed at the end of the book. As most students do not have Malay-English dictionaries, if they miss a point in class or fail to memorize the meaning of a word, they have to use Google Translate to quickly find the meaning of that word or understand the sentence. This way Google Translate has a great facilitating role in students' improvement.

\subsection{Participants and Instrument}

The participants of the study were a group of 17 international students from various fields and backgrounds who had registered for the LKM 100 Bahasa Malaysia (I) course at the School of Languages, Literacies, and Translation, USM. The instrument used was a questionnaire (See, Appendix A) developed by the researchers and the subjects were asked to fill out the 15-item instrument, of which 12 items were on a Likert scale and 3 items were subjective questions, concerning their experience of using Google Translate as a supplementary tool for learning Malay. Out of these, 16 questionnaires were returned completely giving a return rate of $94.1 \%$ for the participants.

The collected data were analyzed using PASW Statistics software (SPSS) version 18 for descriptive statistics. The average Cronbach's Alpha coefficient of reliability for the Likert scale of the questionnaire was 0.678, hence quite acceptable reliability of the instrument. Factor analysis for the construct validity of the questionnaire could not be run due to the low number of participants of the case study. This, however, was not the aim of our research. The subjective items also yielded important results regarding the kinds of classroom tasks and activities that the students can potentially benefit from when using Google Translate as an additional tool for learning Malay.

\section{Results}

The results of the survey are depicted in table 2. As the last two columns of the table show the average means for the listening and speaking items of the questionnaire are 2.28 and 2.78 respectively suggesting that most participants of the study disagreed with using Google Translate for learning listening and speaking skills.

However, the average means for the reading and writing items of the survey are 4.40 and 4.96 respectively suggesting that most participants of the study partially agreed with using Google Translate for learning the reading skill and agreed with using it for learning the writing skill.

The participants of the study, nevertheless, slightly disagreed with using Google Translate for learning grammar with an average mean of 3.50, whereas most of them preferred to use it for the learning of vocabulary with an average mean of 5.15. Therefore the answer to the first research question is that most of the participants of the study chose to use Google Translate for learning the vocabulary, writing, and reading skills while they opted not to use it for learning listening, speaking and grammar of Bahasa Malaysia. 
Table 2. Descriptive statistics for the Google Translate Attitude Questionnaire

\begin{tabular}{lccccccc}
\hline Item & $\mathrm{N}$ & Minimum & Maximum & Std. Deviation & Mean & Average Mean & Google Translate Use \\
\hline L1 & 16 & 1.00 & 4.00 & 1.14746 & 2.3750 & Listening & Disagree \\
L2 & 16 & 1.00 & 3.00 & .75000 & 2.1875 & L1+L2 $=2.28125$ & \\
\hline S3 & 16 & 2.00 & 4.00 & .65511 & 2.8125 & Speaking & Disagree \\
S4 & 16 & 2.00 & 4.00 & .57735 & 2.7500 & S3+S4 = 2.78125 & \\
\hline R5 & 16 & 3.00 & 6.00 & .79320 & 4.3125 & Reading & Partially Agree \\
R6 & 16 & 3.00 & 6.00 & .96609 & 4.5000 & R5+R6 $=4.40625$ & \\
\hline W7 & 16 & 3.00 & 6.00 & .99791 & 4.9375 & Writing & Agree \\
W8 & 16 & 3.00 & 6.00 & .96609 & 5.0000 & W7+W8 $=4.96875$ & \\
\hline G9 & 16 & 1.00 & 5.00 & 1.14746 & 3.3750 & Grammar & Slightly Disagree \\
G10 & 16 & 1.00 & 5.00 & 1.08781 & 3.6250 & G9+G10=3.50000 & \\
\hline V11 & 16 & 3.00 & 6.00 & .95743 & 5.1250 & Vocabulary & Agree \\
V12 & 16 & 3.00 & 6.00 & .83417 & 5.1875 & V11+V12 $=5.15625$ & \\
\hline
\end{tabular}

In order to investigate the second research question Pearson Correlation was run between selected learners' overall scores in the Google Translate attitude questionnaire and their midterm examination scores and the results are shown in the following table. It should be mentioned that the researchers did not have access to the learners' final examination scores and hence the midterm examination scores were used.

Table 3. Pearson correlation between the variables

\begin{tabular}{llcc}
\hline & & Overall Mean & Midterm Score \\
\hline Overall Mean & Pearson Correlation & 1 & $.875^{* *}$ \\
& Sig. (2-tailed) & & 000 \\
& $\mathrm{~N}$ & 16 & 16 \\
\hline Midterm Score & Pearson Correlation & $.875^{* *}$ & 1 \\
& Sig. (2-tailed) & 000 & \\
& $\mathrm{~N}$ & 16 & 16 \\
\hline **. Correlation is significant at the 0.01 level (2-tailed)
\end{tabular}

**. Correlation is significant at the 0.01 level (2-tailed).

Table 3 above depicts that there was a strong positive correlation $(\mathrm{r}=0.875, \mathrm{p}<0.01)$ between the two variables. Consequently, we can state that there was a significant relationship between selected learners' overall scores in the Google Translate attitude questionnaire and their midterm examination scores, which means that those learners who achieved higher scores in the LKM 100 Bahasa Malaysia (I) midterm examination had a more positive attitude towards using Google Translate as a supplementary tool for language learning.

The third research question deals with how the selected learners perceive the benefits and/or problems of using Google Translate as a supplementary tool in language learning. Qualitative data from the subjective items 13, 14, and 15 of the questionnaire were analyzed. Then the main points and opinions with higher frequencies of occurrence in students' written comments were summarized as the following:

\subsection{What Are the Benefits of Using Google Translate (GT) As a Supplementary Tool for Learning Malay?}

Many learners have expressed their beliefs regarding the positive experiences they had when using Google Translate. These examples are taken from their answers to the above question:

“- After using GT I am more encouraged to learn Malay;

- GT facilitated my Malay learning to a large degree;

- I feel more prepared and less threatened in class when answering questions;

- GT makes me more active to participate in my classroom;

- Learning is easier and more fun this way;

- It is good for my self-learning even after the class ends;

- I used GT to write my semester essays and it helped me a great deal;

- Using GT, I feel relaxed because I don't worry to ask the meaning of all words in class; 
- GT is quite accessible everywhere so I feel the teacher is always next to me;

- GT really solved most of my problems with vocabulary, and writing;

- I used GT for my classroom presentation and it was great, etc!"

3.2 What Are the Problems of Using Google Translate (GT) as a Supplementary Tool for Learning Malay?

Some students faced problems when using Google Translate as a supplementary tool for learning Malay. The most important points they made in answer to the above question are the following:

“- I think GT is good for translating words or writing essays but it is not good for practicing speaking;

- I guess somebody should first teach me how to use GT for language learning;

- To use GT I need to have access to the Internet outside the university, which is sometimes difficult;

- GT provides English pronunciations of words and sentences but unfortunately it does not provide those of Malay;

- This kind of learning cannot do the job of the teacher;

- I found no grammatical explanations in GT;

- GT translations are not always reliable, etc."

3.3. Overall Attitudes towards Using Google Translate (GT) as a Supplementary Tool for Learning Malay

Generally most participants of the study had a positive attitude towards using Google Translate as a supplementary tool for learning Malay. These are summarized as the following:

“- I strongly believe that GT is the best tool for learning a new language;

- If someone teaches me about the potentials of this technology I can use it more effectively;

- I would like to suggest GT as a new medium of learning to all of my friends;

- I think GT and other online technologies must be used for language learning;

- I already used GT for translation now I found it great for language learning, etc.”

However, some students have expressed doubts regarding the role of the technology, such as: "I think these new tools can never replace classroom teachers!"

\section{Discussion \& Conclusion}

In light of what Dagiliene (2012) and Cook (2010) have mentioned about the revival of translation approaches as a result of the needs of the modern world, this study can further support that translation technologies can benefit Malay language learner. It also backs up some earlier research (Groves \& Mundt, 2015; Garcia \& Pena, 2011), which state that Google Translate can be helpful for introductory courses in which beginners strive to learn the basics of a new language especially for written skills. However, this study corroborates the findings of Josefsson (2011) that Google Translate may not be a useful tool for the learning of grammar.

Considering the above-stated findings there is strong evidence that Google Translate can be used as a supplementary tool for learning Malay for several reasons. First, most of the selected language learners in the study found great benefits in using Google Translate as a supplementary tool for learning the Bahasa Malaysia (I) course. Second, the findings are based on actual experiences of students as active Google Translate users. Third, the resultant positive aspects of using GT are based on the basic assumptions and principles of constructivism (Gilakjani, et al. 2013; Juniu, 2006; Kim, 2005), which emphasize students construct their own way of understanding and knowledge of the world, reflect on their own approaches to solving problems, and fostering the ability for lifelong learning. However, in order to eliminate the problems mentioned by the participants of the study further research is required to provide a tangible and practical framework within which the mechanism and methodology for integrating new language learning technologies, including Google Translate, can be implemented into the course curriculum. Moreover, as students mentioned in the subjective item 14, some learners may need instructions and assistance by the teachers regarding how to optimally benefit from these new language learning technologies.

In conclusion, this study suggests that using Google Translate as a supplementary tool for learning Malay is a strategy in which the actual learning experience can be improved for the learners. They can become more engaged and more aware of their own learning and take more responsibility for it. This has also benefits for the teachers, e.g. saving more time and energy. However, we should consider GT's limitations. First, using Google Translate should only be regarded as a learning strategy by language learners and not a replacement for the teacher. Second, there are limitations on the use of GT, as other types of technology, with regard to students' e-learning readiness, availability of Internet access, and both hardware and software applications. Finally, we should consider that although Google Translate is not preferred for learning the oral skills of Malay due to its current limitations, this technology is constantly developing its features so as to provide the learners with an opportunity for learning more skills and components of Malay language in the near future.

\section{Acknowledgements}

This article is published with the support of the Universiti Sains Malaysia (USM) Fellowship. 


\section{References}

Cook, G. (2010). Translation in Language Teaching: An Argument for Reassessment. Oxford: Oxford University Press.

Dagiliene, I. (2012). Translation as a Learning Method in English Language Teaching. Studies about Languages, 21, 124-129. Retrieved from http://dx.doi.org/10.5755/j01.sal.0.21.1469.

Davis, R. (2006). Utopia or Chaos? The Impact of Technology on Language Teaching. The Internet TESL Journal, 12 , (11). Retrieved from http://iteslj.org/Articles/DavisImpactOfTechnology.html.

Garcia, I., \& Pena, M. I. (2011). Machine translation-assisted language learning: writing for beginners. Computer Assisted Language Learning, 24(5), 471-487. Retrieved from http://dx.doi.org/10.1080/09588221.2011.582687.

Gilakjani, A. P., Leong, L. M., \& Ismail, H. N. (2013). Teachers' Use of Technology and Constructivism. International Journal of Modern Education and Computer Science, 2013(4), 49-63.

Google Translate. (2016, February 20). Retrieved from https://translate.google.com/about/intl/en_ALL/languages.html.

Groves, M., \& Mundt, K. (2015). Friend or foe? Google Translate in language for academic purposes. English for Specific Purposes, 37, (2015) 112-121.

Jin, L., \& Deifell, E. (2013). Foreign Language Learners' Use and Perception of Online Dictionaries: A Survey Study. MERLOT Journal of Online Learning and Teaching, 9(4), 515-533.

Josefsson, E. (2011). Contemporary Approaches to Translation in the Classroom: A Study of Students'Attitudes and Strategies. Retrieved from http://du.diva-portal.org/smash/get/diva2:519125/FULLTEXT01.pdf.

Juniu, S. (2006). Use of Technology for Constructivist Learning in a Performance Assessment Class. Measurement in Physical Education and Exercise Science, 10(1), 67-78.

Kim, J. S. (2005). The Effects of a Constructivist Teaching Approach on Student Academic Achievement, SelfConcept, and Learning Strategies. Asia Pacific Education Review, 6(1), 7-19.

Koehn, P. (2009). Statistical Machine Translation. Cambridge: Cambridge University Press.

LKM 100 Course Syllabus (2014). A Guide to Language Courses, School of Languages, Literacies and translation, academic session 2014/2015. Retrieved from https:/www.usm.my/images/pdf_ijazah/biguidebook.pdf.

Richards, J. C., \& Rodgers, T. S. (2001). Approaches and methods in language teaching. Cambridge: Cambridge University Press.

Roche, J. (2010). Mutual Impact - On the Relationship of Technology and Language Learning and Teaching. In C. Ward (Ed.) The Impact of Technology on Language Learning and Teaching: What, How and Why (pp. 44-62). Retrieved from https://epub.ub.uni-muenchen.de/14202/1/14202.pdf.

Tabatabaei, M., \& Gui, Y. (2011). The impact of technology on teaching and learning languages. In A. Méndez-Vilas (Ed.) Education in a technological world: communicating current and emerging research and technological efforts (pp. 513-517). Retrieved from http://www.formatex.info/ict/book/isbn-contents.pdf.

Ur, P. (1996). A Course in English Language Teaching: Practice and Theory. Cambridge: Cambridge University Press.

Watkins, R., Leigh, D., \& Triner, D. (2004). Assessing Readiness for E-Learning. Performance Improvement Quarterly, 17(4), 66-79.

Appendix A. Google Translate Attitude Questionnaire

\begin{tabular}{|c|c|c|c|c|c|c|c|}
\hline Sub-Scales & $\begin{array}{l}\text { Instructions: Please tick or circle around "only one" choice (number) } \\
\text { among the alternatives, in which " } 1=\text { Strongly Disagree", " } 2= \\
\text { Disagree", " } 3=\text { Slightly Disagree", " } 4=\text { Partially Agree" " } 5=\text { Agree", } \\
\text { and "6 = Strongly Agree". There are no "right" or "wrong" answers. We } \\
\text { highly appreciate your "honest" choices for items } 1 \text { to } 12 \text { and your } \\
\text { "honest" answers to questions } 13 \text { to } 15 \text {. Thank You! }\end{array}$ & 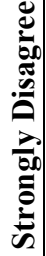 & 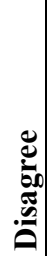 & 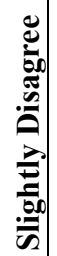 & 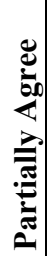 & 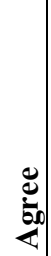 & 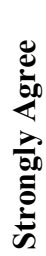 \\
\hline \multirow{2}{*}{$\begin{array}{c}\text { Google } \\
\text { Translate } \\
\text { Use for } \\
\text { Learning } \\
\text { Listening }\end{array}$} & $\begin{array}{l}\text { 1. Google Translate can be used as a supplementary tool for practicing } \\
\text { listening. }\end{array}$ & 1 & 2 & 3 & 4 & 5 & 6 \\
\hline & $\begin{array}{l}\text { 2. I use Google Translate to listen and understand Malay words and } \\
\text { sentences. }\end{array}$ & 1 & 2 & 3 & 4 & 5 & 6 \\
\hline \multirow{2}{*}{$\begin{array}{c}\text { Google } \\
\text { Translate } \\
\text { Use for } \\
\text { Learning } \\
\text { Speaking }\end{array}$} & $\begin{array}{l}\text { 3. Google Translate can be used as a supplementary tool for practicing } \\
\text { speaking. }\end{array}$ & 1 & 2 & 3 & 4 & 5 & 6 \\
\hline & 4. I use Google Translate to pronounce Malay words and sentences. & 1 & 2 & 3 & 4 & 5 & 6 \\
\hline
\end{tabular}




\begin{tabular}{|c|c|c|c|c|c|c|c|}
\hline \multirow{2}{*}{$\begin{array}{l}\text { Google } \\
\text { Translate } \\
\text { Use for } \\
\text { Learning } \\
\text { Reading }\end{array}$} & $\begin{array}{l}\text { 5. Google Translate can be used as a supplementary tool for practicing } \\
\text { reading. }\end{array}$ & 1 & 2 & 3 & 4 & 5 & 6 \\
\hline & $\begin{array}{l}\text { 6. I use Google Translate to read and understand Malay words and } \\
\text { sentences. }\end{array}$ & 1 & 2 & 3 & 4 & 5 & 6 \\
\hline \multirow{2}{*}{$\begin{array}{c}\text { Google } \\
\text { Translate } \\
\text { Use for } \\
\text { Learning } \\
\text { Writing }\end{array}$} & $\begin{array}{l}\text { 7. Google Translate can be used as a supplementary tool for practicing } \\
\text { writing. }\end{array}$ & 1 & 2 & 3 & 4 & 5 & 6 \\
\hline & 8. I use Google Translate to write Malay words, sentences, and essays. & 1 & 2 & 3 & 4 & 5 & 6 \\
\hline \multirow{2}{*}{$\begin{array}{c}\text { Google } \\
\text { Translate } \\
\text { Use for } \\
\text { Learning } \\
\text { Grammar }\end{array}$} & $\begin{array}{l}\text { 9. Google Translate can be used as a supplementary tool for learning } \\
\text { Malay grammar. }\end{array}$ & 1 & 2 & 3 & 4 & 5 & 6 \\
\hline & 10. I use Google Translate to do my exercises and drills correctly. & 1 & 2 & 3 & 4 & 5 & 6 \\
\hline \multirow{2}{*}{$\begin{array}{c}\text { Google } \\
\text { Translate } \\
\text { Use for } \\
\text { Learning } \\
\text { Vocabulary }\end{array}$} & $\begin{array}{l}\text { 11. Google Translate can be used as a supplementary tool for learning } \\
\text { Malay vocabulary. }\end{array}$ & 1 & 2 & 3 & 4 & 5 & 6 \\
\hline & $\begin{array}{l}\text { 12. I use Google Translate to understand the meaning and usage of Malay } \\
\text { vocabulary. }\end{array}$ & 1 & 2 & 3 & 4 & 5 & 6 \\
\hline
\end{tabular}

13. In your opinion, what are the benefits of using Google Translate as a supplementary tool for learning Malay? (Please use examples)

14. In your opinion, what are the problems of using Google Translate as a supplementary tool for learning Malay? (Please use examples)

15. What is your overall attitude towards using Google Translate as a supplementary tool for learning Malay? (Please use examples) 